\title{
Burnout and psychiatrists: what do we know and where to from here?
}

\author{
S. Kumar* \\ Waikato Clinical School, University of Auckland, Auckland, New Zealand
}

\begin{abstract}
Medicine in most parts of the world is becoming a stressful profession. Psychiatrists represent a high-risk group among doctors for experiencing burnout, alcohol and drug use, posing suicide risk and other forms of work-related stress. There are reports that entrants in the profession of psychiatrists are decreasing globally. Conceptual issues related to burnout are explored and factors contributing to burnout in psychiatrists are reviewed. Methodologically sound studies are needed to help us understand positive aspects of psychiatry as a profession and the environment psychiatrists work in. Effective treatment programmes for burnout are also needed not only to reduce suffering but also to retain psychiatrists in the profession.
\end{abstract}

Key words: burnout, psychiatrists, occupational stress, emotional exhaustion.

\section{Introduction}

Increasing rates of mental disorders, substance abuse, suicide and consequent impairment in functioning among doctors are well recognised. This has resulted in professional bodies like Canadian Psychiatric Association to issue position papers on treating impaired physician (Myers, 1997, 2008). In keeping with the Hippocratic tradition many doctors place their patients before themselves. Their work exposes them to a plethora of emotions, including a need to rescue the patient, a sense of failure and frustration when the patient's illness progresses, feelings of powerlessness against illness and its associated losses, grief, fear of becoming ill oneself or a desire to separate from and avoid patients to escape these feelings (Meier et al., 2001). These emotions, powerful in nature and capable of causing distress, arise from the doctorpatient relationship.

Doctors are also exposed to stressors from outside the doctor-patient relationship. They have to work in an increasingly litigious and unforgiving environment (Myers, 2008). Bureaucratic requirements imposed upon them are increasing and medical knowledge is advancing rapidly with which doctors have to constantly keep in touch (Hughes et al., 2002). A recent publication by the World Medical Association has observed 'physicians in many countries are experiencing

* Address for correspondence: Dr Shailesh Kumar, Consultant Psychiatrist and Clinical Associate Honorary Professor, Waikato Clinical School, University of Auckland, Private bag 3200, Hamilton New Zealand.

(E-mail: shailesh.kumar@waikatodhb.health.nz) great frustration in practising their profession, whether because of limited resources, government and/or corporate micro-management of healthcare delivery, sensationalist media reports of medical errors and unethical physician conduct, or challenges to their authority and skills by patients and other healthcare providers' (WMA, 2009, p. 114).

Furthermore, doctors are finding themselves working in an environment or in roles for which they were not trained. Service delivery is changing from an office-based model to a population-based health model. Doctors have to fulfil administrative duties, such as dealing effectively with workforce issues, often in addition to their significant clinical commitments (Hughes et al., 2002). Fulfilling unaccustomed tasks creates stressors and it would appear that constantly changing work environment predisposes doctors to experiencing high levels of stress.

Such chronic exposure to stressors arising from work causes burnout. Burnout now a term in common usage, was first coined by Freudenberger (1974) to describe the emotional exhaustion experienced by workers in the public services. Over the last 30 years, research literature on this topic has accumulated and, according to one estimate, over 2500 publications on burnout had appeared by 1999 (Carson et al., 1999). It is noteworthy that most of these publications have restricted the definition of burnout to human-service workers, a trend that acknowledges the unique pressures of utilising one's self as the 'tool' in face-to-face work with needy, demanding and often troubled clients (Carson et al., 1999). Doctors fall in this category of professionals at high risk of experiencing burnout.

Psychiatrists represent a special group among doctors who may be particularly vulnerable to burnout - more 
so than their counterparts in other disciplines (Snibbe et al., 1989; Deary et al., 1996; Myers, 2008). Findings from these studies have not yet ascertained whether it is the nature of the work or the environment psychiatrists practice in or it is their personality structure that makes them susceptible to experiencing stress.

We do know that psychiatry has undergone significant and rapid change in a relatively short period of time, which may mean constant adaptation to new ways of working for many psychiatrists (Hafner, 2002). Psychiatry has also changed from being a custodial to a therapeutic discipline. Simultaneously, the expectations of society have also increased dramatically: people seek psychiatric help not only for relief from disorder but also for manifold problems of everyday life whereas many psychiatrists may not feel equipped or comfortable in taking on such roles (Hafner, 2002). Some of these changes in philosophy and expectations may have occurred three or four decades ago, but their full impact on service delivery may still be current. Professional requirements to be met by psychiatrists have increased quantitatively and qualitatively with the change from a caring, paternalistic attitude towards the mentally ill to a therapeutic partnership (Hafner, 2002). Relatives of mental-health patients on the other hand widely harbour unrealistic expectations of therapy outcomes (Lozinskaia, 2002). Psychiatrists in many developed countries report excessive workload which they try to deliver in grossly inadequate and underfunded mental health services (Bressi et al., 2009). There is an increasing expectation from the society that psychiatrists ought to be precise in predicting risk of violence and suicide among their patients even though the task of predicting is well recognised to be fraught with difficulty (Mellsop \& Kumar, 2008).

Almost in parallel with such trend psychiatrists report being distressed by a higher frequency of face-to-face and often aggressive interactions with patients (Lasalvia et al., 2009). Perceived unfairness at workplace, higher frequency of face-to-face interactions with patients and weak workgroup cohesion are reported to affect burnout in psychiatrists (Lasalvia et al., 2009). The profession of psychiatry may be becoming stressful for many practitioners. Not paying urgent attention to the growing problem of burnout in psychiatrists may have dire consequences for the profession that is already facing diminishing entrants and stigma (Kendell \& Pearce, 1997; Storer, 2002; Roberts, 2010).

\section{What is burnout?}

It is worth examining some of the concepts around burnout at this stage. Various definitions of burnout have emerged in the last three decades. Kuremyr et al. (1994, p. 676) proposed a uni-dimensional model of burnout, which was based on exhaustion. They defined burnout as 'an experience of physical, emotional and mental exhaustion caused by longterm involvement in situations that are emotionally demanding'. This definition was based on the work by Pines \& Aronson (1988). Lee \& Ashforth (1990) defined burnout as a syndrome of emotional exhaustion, depersonalisation and feelings of low personal accomplishment. This definition was based on Maslach \& Jackson's (1986) work, which used a threedimensional model of burnout by adding two dimensions of depersonalisation and reduced personal accomplishment to the dimension of exhaustion. Emotional exhaustion (tiredness, somatic symptoms, decreased emotional resources and a feeling that one has nothing left to give to others) is used to mean people feeling emotionally overextended and exhausted by their work, 'Depersonalisation' describes when people develop negative, cynical attitudes and impersonal feelings towards their clients, treating them as objects, and 'reduced Personal Accomplishments' denote feelings of incompetence, inefficiency and inadequacy. The higher the Emotional Exhaustion and Depersonalisation scores and the lower the Personal Accomplishment scores, the more a physician would be suffering from burnout. This definition of burnout has been the most widely used in psychiatric literature and will be used here.

\section{Why do we experience burnout?}

We also need to understand why, when faced with chronic work stress, does one develop burnout? The symptoms of burnout have been hypothesised to appear in order to protect human psyche against further damage in the face of 'having no way out'. Freudenberger (1983) describes depersonalisation as a means of protection against further emotional drowning or a homoeostatic mechanism in an emotionally exhausted worker. Along similar lines, one may argue that emotional exhaustion acts as a 'brake' to stop burnout individuals who may not know how or when to slow down. Negative changes in attitude (reduced work goals, loss of idealism, heightened self-interest and increasing emotional detachment from clients) have been described by Benbow (1998) as forms of coping. Huggard (2003) has suggested that even though disengagement and distancing are often employed as coping mechanisms by people facing burnout, they lead to reduction in empathy. Many doctors believe that detachment from emotional engagement with 
patients is beneficial. Halpern (2001) has identified the main benefits of such detachment: protection against burnout, better concentration, sustained impartiality and objectivity, and better time management. Despite the benefits identified, maintaining empathy in a therapeutic relationship is beneficial and indeed may be preventative against burnout (Halpern, 2001; Huggard, 2003).

But is burnout the only type of reaction one can expect to have when exposed to chronic work stress? Exposure to specific types of stressor is reported to be associated with certain types of responses which may be different to burnout (McCann \& Pearlman, 1990; Figley, 1995; Pearlman \& Saakvitne, 1995; Cunningham, 2003; Huggard, 2003). Mental health professionals, such as psychiatrists, invariably work with people who have been traumatised and are at high risk of vicarious traumatisation. Vicarious traumatisation describes the impact of repeated empathic engagement with trauma survivors and associated cognitive, schematic and other psychological effects (McCann \& Pearlman, 1990). Symptoms associated with vicarious traumatisation include anxiety, disconnection and avoidance of social contact, becoming judgemental, depression, somatisation and disrupted belief about self (Pearlman \& Saakvitne, 1995; Cunningham, 2003). While some symptoms of vicarious traumatisation may appear to overlap with burnout, causation differs. Burnout may be caused by stresses associated with factors such as caseload and institutional stress, whereas vicarious traumatisation occurs due to counter-transference issues by virtue of working with or even repeated exposure to traumatic client material (Stamm, 1997).

Compassion fatigue is another term often described in the literature on occupational stress among professionals working with traumatised patients. It encompasses more advanced psychological disruption and is used interchangeably with secondary-traumatic stress disorder. Symptoms of secondary traumatic stress disorder are said to be identical to posttraumatic stress disorder, including those of intrusion, avoidance and arousal that may occur even after exposure to one incident (Figley, 1995). Two coping skills, sense of achievement and emotional disengagement, are said to protect against compassion fatigue, whereas prolonged exposure to traumatic materials, traumatic recollections and life disturbances leads to its development. New evidence has also emerged to suggest that rather than exposure to patients' traumatic experiences it is work-related stress that best predicts burnout among psychiatrists (Devilly et al., 2009). Management process (workgroup cohesion) and two working life areas (fairness and control) were the strongest predictors of burnout in another study
(Lasalvia et al., 2009). Systemic as well as sociodemographic factors perpetuate burnout among psychiatrists.

\section{What are the consequences of burnout in psychiatrists?}

We still fully do not understand the consequences of burnout in psychiatrists. Majority of the research on this topic has focused on causative or protective factors for burnout in psychiatrists (Guthrie et al., 1999; Holloway et al., 2000; Fothergill et al., 2004; Kumar et al., 2005). Lately some studies have focused on intervention strategies, but no methodologically sound studies have examined the immediate consequences of burnout on psychiatrists or their patients. In the absence of longitudinal data, the literature on consequences of burnout has largely evolved from crosssectional or anecdotal reports. Caution needs to be exercised in interpreting causality from these studies because most of them describe factors that are associated with burnout in a cross-sectional survey of participants. Alternatively, they describe opinions of researchers or study participants about the consequences of burnout without providing any objective evidence of their occurrence or prevalence.

Studies on burnout in other professions suggest that high levels of emotional exhaustion is associated with a range of somatic symptoms such as headaches and sleep disturbances (Dell'Ebra et al., 1994; Burke \& Greenglass, 1988) or the intention to leave work (Lee \& Ashforth, 1990). Psychiatrists as a group are reported to be at a significantly higher risk of substance abuse, depression, suicide and dysfunctional behaviour including risk of developing sexual relationship with patients than other disciplines (Firth-Cozens, 2007; Myers, 2008) and stress or burnout may be a contributing factor for such problems. Burnout in psychiatrists, therefore, has significant implication for the future of delivery of mental health (Wykes et al., 1997).

Psychiatrists may suffer a direct consequence of burnout reported in other professions, namely decline in professional idealism and coping mechanisms. Golliher (1995) in a study of burnout in psychiatrists and psychologists hypothesised that as clinical experience increases, idealism and stress decrease, and the use of coping mechanisms increases. This study surveyed first-year psychiatric residents and first-year clinical psychology doctoral students (low-experience level), third-year residents and clinical psychology interns (medium-experience level) and clinical psychologists and psychiatrists (high-experience level) to determine their attitudes towards the mental-health profession. Their answers were analysed through 
analysis of variance by the level of experience and discipline (clinical psychology or psychiatry) to determine significant differences in idealism, burnout levels and coping mechanisms. As predicted, clinicians with low-experience level were more stressed, more idealistic and used fewer coping techniques than those with high-experience level. The results for the medium-experience group were equivocal. Significant differences between clinical psychology and psychiatry included higher stress for psychiatrists and differences in the areas in which clinical psychologists and psychiatrists were idealistic. Significant interactions between the level of experience and discipline suggested a different progression through the three levels of experience for clinical psychology than for psychiatry (Golliher, 1995). A similar inverse relationship between burnout and clinical experience has been reported in two recent studies. Martini et al. (2004) compared burnout levels among residents in different medical specialities and found that $77.3 \%$ of first-year residents as opposed to $41.8 \%$ of second-year residents met criteria for burnout using Maslach Burnout Inventory. The authors, however, did not define what they meant by 'criteria for burnout'. Woodside et al. (2008), on the other hand, reported an inverse correlation between age and scores on depersonalisation subscale of Maslach Burnout Inventory in an American study of burnout in family medicine and psychiatry residents.

Absenteeism, productivity problems, job dissatisfaction, lower quality of care, adverse work environment, lowered retention of skilled staff as well as poor patient care and patient dissatisfaction have been identified as consequences of burnout in health professionals in general. More than half of the respondents in a Canadian study were considering relocating due to burnout (Thommasen et al., 2001). In another study of Community Mental Health Nurses, one-quarter of respondents were found to possess negative attitudes towards their clients, and approximately one in seven experienced little or no sense of satisfaction with their work (Hannigan et al., 2000). Whether or not these factors apply to psychiatrists remain to be seen.

Another effect of burnout could be on job satisfaction; as burnout increases job satisfaction decreases and vice-versa. A survey of 96 community mental health centre $(\mathrm{CMHC})$ psychiatrists found that many suffered from burnout: 46 expressed dissatisfaction with their work in CMHCs, 14 expressed satisfaction, seven had mixed feelings, whereas the remaining respondents gave 'diverse responses' that did not fit into any clear category (Vaccaro \& Clark, 1987). Factors contributing to dissatisfaction included lack of administrative support and validation, low pay, responsibility without authority and pressure to sign documents related to patients unknown to them. Factors contributing to satisfaction were having a variety of tasks, being valued for having uniquely comprehensive experience, being supported in the clinical oversight role, being in charge of CMHC operations and working in a CMHC affiliated with an academic centre or the medical community (Vaccaro \& Clark, 1987). From the studies reviewed above, a relationship between burnout and job satisfaction appears tentative (Vaccaro \& Clark, 1987; Golliher, 1995). A more definitive relationship has recently emerged from an Italian study of burnout among 81 psychiatrists working in the Italian public mental health system (Bressi et al., 2009). These authors reported a low score on the job satisfaction section of Job Diagnostic Survey predicted high scores on the Emotional Exhaustion subscale of Maslach Burnout Inventory, implying that job satisfaction may have a protective effect against burnout in psychiatrists. In other words, the relationship between burnout and job satisfaction in psychiatrists is poorly understood and often contradictory.

\section{Where to from here?}

A number of studies have investigated the factors that are associated with, or cause, stress in psychiatrists (Bressi et al., 2009; Lasalvia et al., 2009; Kumar et al., 2011). While such studies have enriched our understanding of the subject, we need to move on to understanding the factors that create a positive work environment and protect psychiatrists against work stress. Applying Job Demands Resource Model, an emerging concept in recent scientific literature, to psychiatrists' work environment may give us some answers. This model brings the well being and ill health of employees along with antecedents and consequences of well being and ill health together (Hakanen et al., 2008) and can be applied to any type of work and categorises the aspects of the job which affect stress into two groups: Job Resources and Job Demands (Hakanen et al., 2008). Job Resource refers to the physical, psychological, social and organisational factors that reduce job demands, assist in achieving work goals and stimulate personal growth. They do this by enhancing external motivation (necessary for dealing with job demands and achieving goals) and internal motivation (by fulfilling the basic psychological needs of autonomy, belongingness and competence). Job Demands are those aspects of a job that require sustained physical and or psychological effort. The greater the job demand, the greater the strain on workers. Richness in Job Resources is said to increase work engagement. It can be postulated that this 
study largely looked at 'Job Demands' though some protective factors against burnout were also investigated. By applying the Job Demands Resources model, we may be able to learn more about job resources and protective factors against burnout.

Similarly, we also need to understand what factors help psychiatrists find enjoyment or a sense of purpose from their work. This phenomenon has been described as work engagement (Bakker et al., 2008). Such investigation may help us learn about the factors that prevent burnout in psychiatrists. Work engagement is a concept that is increasingly used in the occupational health psychology literature (Bakker et al., 2008). It is a positive attribute and in many ways just the opposite of burnout characterised by vigour, dedication and absorption, each of which have been operationally defined (Hakanen et al., 2008). High levels of mental energy, persistence and resilience are considered to characterise vigour, whereas a sense of significance, enthusiasm, inspiration, pride and challenge characterise dedication. Absorption is characterised by being engrossed in work, which gives rise to the feeling that time at work passes quickly. Learning about factors that enhance vigour, dedication and absorption among psychiatrists will help us learn about work engagement in psychiatrists. It has generally been recognised that engaged workers have high levels of energy and identify strongly with their work (Bakker et al., 2008). Whether psychiatrists who are better engaged with their work would be protected against burnout will need to be seen through future research. The dimension of personal accomplishment in the construct of burnout has been outlined above. A recent literature has described a construct 'Positive Orientation' that captures evaluations about oneself, one's life and one's future (Caprara et al., 2010). It sounds plausible that possession of such attitudes may protect psychiatrists against burnout. Future studies may wish to examine the level of protection offered against burnout by such personality attributes or attitudes.

We also need well-designed studies on intervention strategies against burnout. Two excellent systematic reviews have reviewed the evidence for the effectiveness of various intervention strategies against burnout (Marine et al., 2006; van Wyk \& Pillay-van Wyk, 2010). Stress management programmes are often suggested for managing staff burnout. However, the systematic review by van Wyk \& Pillay-van Wyk (2010) found no evidence of effectiveness of brief stressmanagement training interventions in reducing job stress for health workers. The authors did find lowquality evidence to support the effectiveness of stressmanagement training of moderate intensity (defined as more than $6 \mathrm{~h}$ contact over 1 month) in short-term reduction of job stress levels, but the beneficial effects diminished without booster sessions. The review found strong levels of evidence to support the effectiveness of intensive, long-term stress-management training programmes in reducing the job stress and risk of burnout among a wide range of health workers working in a variety of settings. This review looked at all health care workers and was not limited to psychiatrists alone. The systematic review by Marine et al. (2006) grouped intervention strategies against burnout into person-directed (cognitive behavioural therapy, relaxation, music making, massage and multicomponent programmes) and work-directed (attitude change and communication, support from colleagues, participatory problem solving and decision making, and changes in work organisation). The authors found that there was only limited evidence to support the efficacy of either person- or work-directed intervention strategies in reducing burnout in healthcare workers, but concluded that the benefits of such interventions may be evident for as long as 2 years. This review highlighted the need for good quality intervention studies for burnout.

Combining the two systematic reviews, one could speculate that perhaps an intense stress-management programme with booster sessions delivered over a longer period may yield longer-lasting results in psychiatrists experiencing burnout. Future studies of intervention in burnout and job satisfaction in psychiatrists may wish to compare efficacy of long- and short-term programmes of varying intensities.

\section{Conclusions}

Doctors in general and psychiatrists in particular are prone to experience work-related stress and burnout. Factors related to the work environment appear to play a stronger role in causing burnout in psychiatrists than personal factors. Future studies will need to explore positive aspects of psychiatry as a profession, develop preventative strategies and effective treatment programmes against burnout in psychiatrists if the profession has to survive.

\section{Conflict of interest}

This work is based on an MD thesis submitted to the University of Auckland

\section{References}

Bakker A, Schaufeli W, Leiter M, Taris T (2008). Work engagement: an emerging concept in occupational health psychology. Work and Stress 22, 187-200. 
Benbow S (1998). Burnout: current knowledge and relevance to old age psychiatry. International Journal of Geriatric Psychiatry 13, 520-526.

Bressi C, Porcellana M, Gambini O, Madia L, Muffatti R, Peirone A, Altamura A (2009). Burnout among psychiatrists in Milan: a multicenter survey. Psychiatric Services 60, 985-988.

Burke RJ, Greenglass ER (1988). Career orientations and psychological burnout in teachers. Psychological Reports 63, 107-116.

Caprara GV, Steca P, Alessandri G, Abela JR, McWhinnie CM (2010). Positive orientation: explorations on what is common to life satisfaction, self-esteem, and optimism. Epidemiologia e Psichiatria Sociale 19, 63-71.

Carson J, Maal S, Roche S, Fagin L, De Villiers N, O'Malley P, Holloway F (1999). Burnout in mental health nurses: much ado about nothing? Stress Medicine 15, 127-134.

Cunningham M (2003). Impact of trauma work on social work clinicians: empirical findings. Social Work 48 , 451-459.

Deary I, Agius R, Sadler A (1996). Personality and stress in consultant psychiatrists. International Journal of Social Psychiatry 42, 112-123.

Devilly G, Wright R, Varker T (2009). Vicarious trauma, secondary traumatic stress or simply burnout? Effect of trauma therapy on mental health professionals. Australian and New Zealand Journal of Psychiatry 43, 373-385.

Dell'Erba G, Venturi P, Rizzo F, Porcú S, Pancheri P (1994 April). Burnout and health status in Italian air traffic controllers. Aviation, Space, and Environmental Medicine, 315-322.

Figley CR (1995). Compassion fatigue as secondary traumatic stress disorder: an overview. In Compassion Fatigue: Coping with Secondary Traumatic Stress Disorder in those who treat the Traumatised (ed CR Figley), pp. 1-20. Brunner/Mazel: New York.

Firth-Cozens J (2007). Improving the health of psychiatrists. Advances in Psychiatric Treatment 13, 161-168.

Fothergill A, Edwards D, Burnard P (2004). Stress, burnout, coping and stress management in psychiatrists: findings from a systematic review. International Journal of Social Psychiatry 50, 54-65.

Freudenberger H (1974). Staff burnout. Journal of Social Issues 30, 159-165.

Freudenberger H (1983). Burnout: Contemporary issues, trends and concerns. In Stress and Burnout in the Human Service Professions (ed. B. Farber), pp. 23-28. Anchor Press/ Doubleday: New York.

Golliher E (1995). The relationship of job satisfaction to level of experience of clinical psychologists and psychiatrists. Dissertation Virginia Consortium for Professional Psychology (Old Dominion University), USA. Dissertation Abstracts International: Section B: the Sciences and Engineering, USA: University Microfilms International No. 55(8-B):3587.

Guthrie E, Tattan T, Williams E, Black D, Bacliocotti H (1999). Sources of stress, psychological distress and burnout in psychiatrists: comparison of junior doctors, senior registrars and consultants. Psychiatric Bulletin 23, 207-212.
Hafner H (2002). Psychiatry as a profession (Psychiatrie als Beruf). Der Nervenarzt 73, 33-40.

Hakanen J, Schaufeli W, Ahola K (2008). The job demands-resources model: a three-year cross-lagged study of burnout, depression, commitment, and work engagement. Work and Stress 22, 224-241.

Halpern J (2001). From Detached Concern to Empathy: Humanizing Medical Practice. Oxford University Press: Oxford.

Hannigan B, Edwards D, Coyle D, Fothergill A, Burnard P (2000). Burnout in community mental health nurses: findings from the all-Wales stress study. Journal of Psychiatric and Mental Health Nursing 7, 127-134.

Holloway F, Szmukler G, Carson J (2000). Support systems. Advances in Psychiatric Treatment 6, 226-237.

Huggard P (2003). Secondary traumatic stress: doctors at risk. New Ethicals Journal 6, 9-14.

Hughes D, Burke D, Hickie I, Wilson A, Tobin M (2002). Advanced training in adult psychiatry. Australasian Psychiatry 10, 6-11.

Kendell R, Pearce A (1997). Consultant psychiatrists who retired prematurely in 1995 and 1996. Psychiatric Bulletin 21, 741-745.

Kumar S, Hatcher S, Huggard P (2005). Burnout in psychiatrists: an etiological model. International Journal of Psychiatry in Medicine 35, 405-416.

Kumar S, Hatcher S, Dutu G, Fischer J, Ma'u E (2011). Stresses experienced by psychiatrists and their role in burnout: a national follow-up study. International Journal of Social Psychiatry 57, 166-79.

Kuremyr D, Kihlgren M, Norberg A, Åström S, Karlsson I (1994). Emotional experiences, empathy and burnout among staff caring for demented patients at a collective living unit and a nursing home. Journal of Advanced Nursing 19, 670-679.

Lasalvia A, Bonetto C, Bertani M, Bissoli S, Cristofalo D, Marrella G, Ruggeri M (2009). Influence of perceived organisational factors on job burnout: survey of community mental health staff. British Journal of Psychiatry 195, 537-544.

Lee RT, Ashforth BE (1990). On the meaning of Maslach's three dimensions of burnout. Journal of Applied Psychology 75, 743-747.

Lozinskaia E (2002). Study of stress parameters in the work of the clinical psychiatrist. International Journal of Mental Health 31, 93-98.

Marine A, Ruotsalainen J, Serra C, Verbeek J (2006). Preventing occupational stress in healthcare workers. Cochrane Database of Systematic Reviews 4. Art. No.: CD002892. DOI:10.1002/14651858.CD002892.pub2.

Martini S, Arfken C, Churchill A, Balon R (2004). Burnout comparison among residents in different medical specialties. Academic Psychiatry 28, 240-242.

Maslach C, Jackson S (1986). Maslach Burnout Inventory Manual, 2nd edn. Consulting Psychologist Press: Palo Alto.

McCann L, Pearlman LA (1990). Vicarious traumatization: a framework for understanding the psychological effects of working with victims. Journal of Traumatic Stress 3, 131-149. 
Meier DE, Back AL, Morrison RS (2001). The inner life of physicians and care of the seriously III. Journal of American Medical Association 286, 3007-3014.

Mellsop G, Kumar S (2008). An axis for risk management in classificatory systems as a contribution to efficient clinical practice. World Psychiatry 7, 182-184.

Myers M (1997). Treatment of the mentally ill physician. Canadian Journal of Psychiatry 42, insert.

Myers M (2008). Physician impairment: is it relevant to academic psychiatry? Academic Psychiatry 32, 39-43.

Pearlman LA, Saakvitne KW (1995). Trauma and the Therapist: Counter-Transference and Vicarious Traumatisation in Psychotherapy with Incest Survivors. Norton: New York.

Pines A, Aronson E (1988). Career Burnout: Causes and Cures. Free Press: New York.

Roberts LW (2010). Stigma, hope, and challenge in psychiatry: trainee perspectives from five countries on four continents. Academic Psychiatry 34, 1-4.

Snibbe J, Radcliffe T, Weisberger C, Richards M, Kelly J (1989). Burnout among primary care physicians and mental health professionals in a managed health care setting. Psychological Reports 65(3: Pt 1), 775-780.

Stamm BH (1997). Work-related secondary traumatic stress. PTSD Research Quarterly 8, 1-3.
Storer D (2002). Recruiting and retaining psychiatrists. British Journal of Psychiatry 180, 296-297.

Thommasen H, Lavanchy M, Connelly I, Berkowitz J, Grzybowski S (2001). Mental health, job satisfaction, and intention to relocate. Opinions of physicians in rural British Columbia. Canadian Family Physician 47, 737-744.

Vaccaro J, Clark G Jr (1987). A profile of community mental health centre psychiatrists: results of a national survey. Community Mental Health Journal 23, 282-289.

van Wyk B, Pillay-Van Wyk V (2010). Preventive staff-support interventions for health workers. Cochrane Database of Systematic Reviews 3, Art. No. D003541. DOI:10.1002/14651858.CD003541.pub2

Woodside J, Miller M, Floyd M, McGowen K, Pfortmiller D (2008). Observations on burnout in family medicine and psychiatry residents. Academic Psychiatry 32, 13-19.

World Medical Association (WMA) (2009). Medical Ethics Manual, 2nd edn (http://www.wma.net/en/30publications/ 30ethicsmanual/pdf/chap_6_en.pdf). Accessed 24 March 2011.

Wykes T, Stevens W, Everitt B (1997). Stress in community care teams: will it affect the sustainability of community care? Social Psychiatry and Psychiatric Epidemiology 32, 398-407. 